\title{
LA RESPONSABILIDAD DEL FUNCIONARIO PÚBLICO EN LA LEY GENERAL DE CONTROL INTERNO
}

\author{
FEDERICO MONTIEL CASTILLO \\ Universidad Estatal a Distancia, Costa Rica \\ fmontiel@uned.ac.cr
}

\section{RESUMEN}

La responsabilidad del funcionario público es una derivación de un ejercicio ético, responsable y transparente en la Función Pública. La responsabilidad del funcionario_no es única sino que puede tener consecuencias por una misma acción en el campo del derecho civil, penal, administrativo y disciplinario. La Ley General de Control Interno es una norma esencial para garantizar seguridad y transparencia en la Administración Pública, y por lo tanto establece un marco propio de regulaciones para los Funcionarios Públicos como jerarcas y titulares subordinados, así como para el personal de la auditoria interna. De igual forma este marco normativo, tiene dispone su propio cuadro sancionatorio, la jurisdicción disciplinaria y la prescripción de la misma.

PALABRAS CLAVES: RESPONSABILIDAD, FUNCIONARIO PÚBLICO, JERARCA, TITULAR SUBORDINADO, CONTROL INTERNO.

\section{ABSTRACT}

The responsibility of public officials is derived from an ethical, responsible and transparent exercise of their Civil Service. This responsibility is not unique and can have consequences in relation to multiple civil, criminal, administrative and disciplinary fields. The General Law on Internal Control is essential to ensure safety and transparency of public administration standards; therefore, it outlines its own series of regulations for public employees such as supervisors, subordinates and internal auditors. Similarly, this policy framework has its own sanctions, disciplinary jurisdiction, and its own deadlines.
KEYWORDS: RESPONSIBILITY, PUBLIC OFFICIAL, SUPERVISOR, SUBORDINATE, INTERNAL CONTROL.

\section{INTRODUCCIÓN}

La sociedad costarricense demanda acciones más claras, contundentes y precisas frente a actos de corrupción que lesionan el Erario Público. Los medios de comunicación colectiva dan a conocer lamentables hechos de corrupción en perjuicio de todos los habitantes de este país. El sistema de control interno se erige como una importante herramienta para colaborar contra la corrupción en la Administración Pública.

La seguridad es un elemento esencial para cualquier organización. Los jerarcas o bien los órganos máximos de toma de decisión necesitan contar con información fidedigna, eficiente y real. En muchas instituciones $u$ organizaciones se ha tomado conciencia de fomentar una cultura que sea proclive hacia el control interno, donde todos los funcionarios participen activamente de la actividades conducentes a fortalecer un clima laboral seguro y con reglas claramente establecidas.

El Sistema de Control Interno es una derivación del principio de legalidad contenido en el Artículo 11 de la Constitución Política y el Artículo 11 de la Ley General de la Administración Pública, donde el ordenamiento jurídico se erige como un "muro o techo" para los limites del poder público y evitar los abusos en su ejercicio. 
Las potestades o las atribuciones en el ejercicio del poder público deben estar claramente establecidas para el funcionario sea el Jerarca o el Titular subordinado, ya que eso representa una traducción concreta del principio de legalidad en su campo de acción, definiendo claramente sus competencias específicas, sus actos o sus conductas administrativas.

Es por esta razón, que la Ley General de Control Interno establece un deber de establecer pautas y comportamientos claros y concretos de los sujetos, definiendo sus responsabilidades y el alcance de la misma. Todo esto debe ser debidamente reglamento, autorizado y aprobado por las autoridades competentes de la entidad $u$ organización pública.

La implementación de la Ley General de Control Interno no ha sido fácil, cada día son más los funcionarios que son conscientes de su necesidad y que la responsabilidad de lograr un clima propicio y robusto de los sistemas de control interno no es algo que compete al jerarca o a las máximas autoridades, sino que todos deben ser partícipes y colaboradores activos para garantizar con estas herramientas un ejercicio más responsable, ético y transparente de la función pública

\section{METODOLOGÍA}

La Metodología de este artículo es descriptiva. En la misma se analizan las disposiciones contenidas en la Constitución Política de Costa Rica (CPCR), la Ley General de Control Interno (LGCI) y la Ley Orgánica de la Contraloría General de la República (LOCGR). De igual forma se complementa con doctrina y con resoluciones judiciales de la Sala Cuarta Constitucional de la Corte Suprema de Justicia, así como con resoluciones administrativas de órganos consultivos como la Procuraduría General de la República (PGR) y la Contraloría General de la República (CGR).
Para efectos de esta investigación se solicitó al Área de Denuncias de la Contraloría General de la República la información referida de cuantas denuncias contra funcionarios públicos han ingresado desde el año 2009 a febrero 2014. En Oficio DFOE-DI-470 del 27 de febrero 2014, indicaron:

TABLA 1

\section{CANTIDAD DE DENUNCIAS INGRESADAS DEL 2009 A FEBRERO 2014}

\begin{tabular}{|c|c|}
\hline Año & $\begin{array}{c}\text { Cantidad de denuncias } \\
\text { anuales }\end{array}$ \\
\hline 2009 & 765 \\
\hline 2010 & 720 \\
\hline 2011 & 702 \\
\hline 2012 & 954 \\
\hline 2013 & 809 \\
\hline 2014 & $110^{*}$ \\
\hline Total general & 4060 \\
\hline
\end{tabular}

Fuente: Elaboración del Sistema de Denuncias (SIDE), Contraloría General de la República

En la Tabla 1 se denota que el ente Contralor recibe una cantidad importante de denuncias en contra de funcionarios públicos, y eso llama a una importante reflexión sobre los incumplimientos a los deberes en la función pública, teniendo en cuenta que ningún ciudadano puede alegar desconocimiento de la Ley, y mucho menos un funcionario público.

También se solicitó a la CGR que indicara, cuantas denuncias una vez superado el análisis de admisibilidad se convierten en expedientes administrativos para investigación formal. En el mismo oficio de marras se indican los datos en la tabla 2. 
TABLA 2

\section{CANTIDAD DE EXPEDIENTES TRAMITADOS POR AÑO}

\begin{tabular}{|c|c|c|}
\hline Año & Iniciados & Finalizados* \\
\hline 2008 & 63 & 88 \\
\hline 2009 & 75 & 79 \\
\hline 2010 & 124 & 116 \\
\hline 2011 & 95 & 93 \\
\hline 2012 & 140 & 44 \\
\hline 2013 & 104 & 26 \\
\hline
\end{tabular}

Fuente: Base de datos de la División Jurídica, suministrado por el área de Denuncias de la Contraloría General de la República, Costa Rica.

De la información suministrada sirve de especial referencia para abordar el tema de la responsabilidad del funcionario público contenida en la Ley General de Control Interno, ya que estas normas jurídicas disponen una especial responsabilidad de la contenida en la Ley General de la Administración Pública.

\section{Aspectos generales del régimen de responsabilidad del funcionario público}

La responsabilidad del funcionario público tiene un amplio desarrollo en la doctrina nacional, así como en la jurisprudencia de los Tribunales de Justicia, y otros entes consultivos de la Administración.

El funcionario público es aquella persona que presta sus servicios de manera personal, remunerada y por acto legítimo de envestidura (Art.2 Ley contra la Corrupción y el Enriquecimiento llícito en la función pública). El funcionario debe cumplir de forma positiva todos los deberes que sean propios de su cargo, para el buen cumplimiento de los servicios que presta al Administrado. En general, todos los funcionarios públicos tienen que orientar su gestión al "deber de probidad", el cual llama a un comportamiento ético, de buena fe, transparente, y leal con su patrono, sea en este caso el Estado (Articulo 3 de la Ley contra la corrupción y el enriquecimiento ilícito en la función pública ).

Estos deberes emanan de la norma fundamental de la organización del Estado Costarricense, siendo el principio de legalidad contenido en el Artículo 11 de Constitución Política un mandato que ordena el sometimiento del funcionario público a la Ley, y poniendo un límite claro a los poderes de la administración frente al Administrado. De igual forma encontramos réplica de este principio en el Articulo 11 de la LGAP.

Toda imposición de eventuales sanciones a los funcionarios públicos, debe darse respetando las garantías del debido proceso que contiene el Artículo 39 de la Constitución Política. Esta importante norma, ha instaurado una serie de principios de obligatorio cumplimiento en todos los procedimientos administrativos sancionatorios, por medio del cual la Administración valorara la imposición de una sanción al funcionario, la cual puede ir desde una simple amonestación hasta la suspensión o despido sin responsabilidad patronal.

En este aspecto, la Sala Cuarta Constitucional de Costa Rica ha indicado: "(...) el debido proceso genera exigencias fundamentales respecto de todo proceso o procedimiento, especialmente tratándose de los de condena, de los sancionadores en general, y aún de aquellos que desembocan en una denegación, restricción o supresión de derechos o libertades fundamentales (...)" (Voto 2000-07203 de las 9:10 horas del 18 de agosto del 2000). De igual forma, la Sala Constitucional reitera la obligatoriedad de la aplicación de estos principios en la Resolución n. ${ }^{\circ}$ 2945-94 de las 8:12 horas del 17 de junio 1994.

En cuanto a la PGR, pueden verse los pronunciamientos n. ${ }^{\circ}$ C-034-1999 del 5 de Febrero de 1999, C-112-2000 del 17 de mayo del 2000 y el C-374-2004 del 10 de diciembre del 2004. 
Para García (2000), los principios inspiradores del orden penal son de aplicación "con ciertos matices, al Derecho Sancionador, dado que ambos son manifestaciones del ordenamiento punitivo del Estado". ( p. 166)

Según Nieto (2002), menciona que "los principios a los que el Derecho Penal debe someterse para satisfacer los postulados del Estado de Derecho, son principios declarados por la Constitución como fundamentales" (p. 168).

Expresando lo que indican ambos autores, estos principios que son propios del derecho penal, una vez que son utilizados por el Derecho Administrativo Sancionador, no son más que una expresión de derechos fundamentales que están contenidos en la Constitución Política, como es el caso de Costa Rica.

Señala Escola (1981), que "si en un proceso penal la situación del imputado debe ser garantizada a fin de que no sufra menoscabo de su vida, libertad y la inocencia, no es menos cierto que en el proceso administrativo, en el cual los particulares deben enfrentarse a la Administración Pública y a todo el aparato y poder que ésta posee, también es necesario que el administrado goce de garantías que le permitan accionar en defensa de sus derechos e intereses en forma efectiva y con el necesario respaldo jurídico". ( p.143)

Estos principios (previamente citados) se sintetizan en los siguientes aspectos:

1. Principio de Intimación e Imputación: intimación consiste en el acto por medio del cual se pone en conocimiento del funcionario una denuncia formal. La Imputación constituye el derecho a una acusación formal, donde se precise en detalle, la forma precisa y la manera clara que se imputa el hecho (ver Votos de la Sala Constitucional 632-1999 y el 2376-1998).
2. Informalidad: se entiende por este sentido, que en materia del procedimiento administrativo, se debe siempre interpretar de la manera más favorable la acción sobre el fondo de la cuestión debatida dejando de lado ritualismos sin sentido. Debe entenderse el procedimiento administrativo como una serie de formas idóneas para encontrar la verdad de real de los hechos, y no como normas sacramentales que entorpezcan el cumplimiento de la justicia (Ver Voto Sala Constitucional 2003-13140 de las 11: 50 horas del 27 de febrero 2004).

3. Motivación de los Actos Administrativos: es una obligación para la administración y un derecho frente al administrado el motivar los actos administrativos. Esto quiere decir, que tiene que indicarse cual es la valoración del contexto que lleva a la administración a adoptar una posición. Esto se encuentra desarrollado en los artículos 129, 136, 220, 274 y 335 de la LGAP (Ver pronunciamientos de la PGR C-342-2004 y C-123-2005).

4. Comunicación de los Actos: todo proceso administrativo nace jurídicamente a la vida a partir del momento que se comunica o notifica según lo indica la Ley. Esto se encuentra en el Artículo 239 LGAP (ver Dictamen 0622000 de la PGR ).

5. Celeridad: los procedimientos administrativos deben cumplirse en los plazos establecidos. Esto por disposición del Artículo 41 de la CPCR que preceptúa el principio de la justicia pronta y cumplida (ver Resolución 2004-0567 de la Sala Constitucional de las 9:15 hora del 14 de mayo del 2004 y de la PGR C-373-2004).

6. Oralidad: este principio se materializa cuando se realiza la Audiencia oral y privada con la administración, momento idóneo para el 
"contradictorio" y ofrecer prueba de descargo. Esto se desprende de los Artículos 309 al 318 LGAP (ver Voto Sala Constitucional 2004-01425).

7. Acceso al Expediente: el expediente de la causa que se investiga debe ser puesto en conocimiento de las partes. Debe estar completo, foliado, en orden y en perfecto estado de conversación (ver Voto Sala Constitucional 2351-1994 y de la PRG OJ-128-2005).

8. Derecho a los Recursos: derecho del funcionario a interponer los recursos administrativos según la Ley frente al acto final del proceso.

En opinión de Brewer (2003) dice que "todos estos principios se constituyen en un principio conocido como "audi alteram partem", el cual significa: el deber siempre de la Administración de oír previamente a los interesados" (p.268)

\section{El aspecto subjetivo como elemento nuclear y tipos de responsabilidades}

Para efectos de imputar la comisión de una falta al funcionario público, se hace necesario precisar los conceptos de potestad sancionatoria disciplinaria y la sancionatoria correccional.

Para (Escola, 1984), "la potestad sancionatoria disciplinaria como la interna de la administración, en cambio la potestad sancionatoria correctiva es externa a la Administración, porque refiere a todas las personas en cuanto incurran en violación o no de las ordenes o mandatos de la Administración" (p.208). En este mismo sentido ver Voto 1264-95 de la Sala Cuarta Constitucional).

Como bien lo indica la Doctrina y la Jurisprudencia nacional, centraremos este estudio en la potestad sancionatoria disciplinaria del agente o funcionario público.
El Artículo 211.1 de la LGAP indica: "El servidor público estará sujeto a responsabilidad disciplinaria por sus acciones, actos o contratos opuestos al ordenamiento, cuando haya actuado con dolo o culpa grave, sin perjuicio del régimen disciplinario más grave previsto por otras Leyes...."

Como se desprende de la norma, para el funcionario público se crea un deber especial de "sujeción" respecto a su marco de actuación y competencias administrativas que le ha dado la Ley. Como elemento central, también se desprende que tiene que existir "culpa grave o dolo" que sea imputable en su accionar. Por dolo, y así ha sido reconocido ampliamente por la Doctrina y Jurisprudencia nacional, se entiende aquel actuar deliberado, mal intencionado, y deseoso de generar un daño en contra del administración o del administrado. Encontramos bajo esta tesitura la desviación o el abuso de poder en algunos casos. Por su parte la "culpa" en general, es una falta al deber de atención, diligencia, prudencia, o cuidado en la realización de las funciones. Para el caso de los funcionarios públicos se agrega la palabra "grave", por lo tanto no es cualquier acción la que va a iniciar la apertura de una investigación o bien la instauración de un procedimiento administrativo, sino que tiene que ser "culpa grave".

Cuando un funcionario público ha desplegado una conducta contraria al ordenamiento jurídico, sea dolosa o con culpa grave, le corresponde la imposición de una sanción que delimita su grado de responsabilidad y el alcance de la misma.

Para este caso concreto, la responsabilidad no es única, y no se limita a la imposición de una acción disciplinaria (llamada de atención, amonestación, suspensión o despido), sino que le pueden ser atribuidas simultáneamente otros tipos de responsabilidad.

En Sentencia 1265-1999 la Sala Constitucional reconoce y avala la multiplicidad de responsabilidades que puede hacer frente el funcionario 
público: "Esta multiplicidad de efectos determina las diferentes clases de responsabilidad del funcionario, la disciplinaria o administrativa, la penal, y la civil o patrimonial. Estas no son excluyentes, por lo que un mismo hecho violatorio de un deber jurídico del servidor puede generar los tres tipos de responsabilidad y por lo tanto, tres tipos de sanciones (...)"

El funcionario público hace frente a varios tipos de responsabilidad y por lo tanto sanciones de la misma especie, cuando ha faltado a sus deberes funcionales con la Administración. Como bien lo menciona la Sala Constitucional, la infracción a los deberes funcionales puede incluso llegar a la vía penal, donde este colaborador puede enfrentar hasta penas privativas de libertad por sus acciones contrarias al ordenamiento jurídico.

\section{LOS TIPOS DE RESPONSABILIDAD FUNCIONAL}

Dentro de la LGAP, como marco normativo que rige en términos generales la responsabilidad del funcionario público, se procede a explicar estos tipos, siendo que el orden en su explicación es meramente aleatorio.

Como se dijera en líneas anteriores, el Artículo 211 de la LGAP establece el deber de sujeción de responsabilidad sea dolosa o culposa del Funcionario, en igual sentido, los Artículos 212 y 213 también de la LGAP. En el Artículo 211 se establece la responsabilidad por delegación, estableciéndose la máxima: "(...) se delega la función, más nunca la responsabilidad". Por su parte el Artículo 213, recoge otra importante máxima en la determinación de la responsabilidad, al indicar que "(...) ante mayor jerarquía, mayor responsabilidad."

1. Responsabilidad Civil: este tipo de responsabilidad se produce cuando el funcionario público con su actuar doloso o con culpa grave produce un daño al Estado y al Administrado.
Este tipo de responsabilidad es de carácter patrimonial del servidor, y por lo tanto deberá responder con sus bienes las consecuencias de sus acciones lesivas. Este tipo de responsabilidad también está relacionada con las disposiciones del Código Civil que establece la relación causal con el daño y la conducta y el deber de reparación.

2. Responsabilidad Administrativa.- en la doctrina se entendía como sinónimos la responsabilidad administrativa de la disciplinaria. La Administrativa se origina y termina en el propio seno de la administración. Nace en el momento en que se determina la apertura de procedimiento sancionatorio administrativo, y termina mediante el acto final que impone una sanción al funcionario, sea desde una amonestación o bien hasta la suspensión el despido sin responsabilidad patronal.

3. La Responsabilidad por Delegación: el artículo 212 de la LGAP establece la responsabilidad por delegación. Cuando un superior delega en un mando inferior la realización de una tarea o labor, no puede desvincularse de su deber de supervisar y fiscalizar la tarea encomendada a su colaborador. Por lo tanto se erige la máxima "(...) se delega la función, mas nunca la responsabilidad." Es una responsabilidad de tipo "personal", ya que recae sobre el superior los deberes máximos de vigilancia, revisión, supervisión y fiscalización.

4. La Responsabilidad Penal: es aquella responsabilidad que se configura cuando la actuación del funcionario público tipifica en una norma penal. En este caso como norma rectora se encuentra el Código Penal, que contempla delitos contra la función pública como el cohecho (propio e impropio), el peculado, la administración fraudulenta, la malversación de fondos públicos, incumplimiento de deberes entre otros. En la nor- 
mativa especial, encontramos importantes disposiciones sancionatorias en la Ley contra la Corrupción y el Enriquecimiento llícito en la función pública, así como en otras normas. Ante el conocimiento de estos hechos, es un deber de la Administración proceder a interponer la denuncia inmediata ante el Ministerio Publico y organismos auxiliares, según Artículo 332 Código Penal.

5. La Responsabilidad Disciplinaria: proviene directamente de la relación sujeción del funcionario con su patrono. Resulta de aplicación inmediata las disposiciones del Reglamento Interior de Trabajo de cada organización, o bien supletoriamente el Código de Trabajo. Este tipo de responsabilidad recae únicamente sobre la disciplina del trabajador, en cambio la responsabilidad administrativa incide sobre la esfera patrimonial.

\section{EL REGIMEN DE RESPONSABILIDAD FUNCIONAL EN LA LEY GENERAL DE CONTROL INTERNO}

Previo a comentar las causales de responsabilidad funcional que contiene la Ley General de Control Interno, se hace necesario esbozar el rol primordial que asume en esta temática la Contraloría General de la República.

La competencia exclusiva que goza la Contraloría General de la República deviene del Artículo 183 de la Constitución Política declarando que es un órgano auxiliar de la Asamblea Legislativa para la vigilancia de la Hacienda Pública, y asignándole independencia funcional y administrativa, así como otras derivadas del Artículo 184 de la carta magna.

Esta independencia funcional se refuerza en la Ley Orgánica de la Contraloría General de la República en su Artículo 2, lo que sin duda brinda un marco sólido en la actuación del ente contralor.
Las facultades de fiscalización sobre la Hacienda Púbica, quedaran claramente estipuladas en el Artículo 8 de la LOGCR, al decir: "La Hacienda Publica estará constituida por los fondos públicos, las potestades para percibir, administrar, custodiar, conservar, manejar, gastar, e invertir tales fondos y las normas jurídicas, administrativas y financieras, relativas al proceso presupuestario, la contratación administrativa, el control interno y externo, y la responsabilidad de los funcionarios públicos (...)".

Como bien lo apunta la norma comentada, la Hacienda Pública se compone un elemento importante para la fiscalización y supervisión del ente contralor, de las normas de contrato interno y externo, señalando para los efectos correspondiente también la responsabilidad del funcionario público.

Este ejercicio prevalente de la función de la CGR, se complementa con la disposición del Artículo 68 de su Ley Orgánica, la cual faculta a la Contraloría a ordenar y recomendar sanciones al órgano o autoridad que considere necesaria cuando a su juicio considere que hay una actuación lesiva en contra en contra de la Hacienda Pública. Dicha recomendación es vinculante para el órgano u autoridad a la cual es dirigida la petición.

Ahora bien, la Ley número 8292 denominada Ley General de Control Interno fue promulgada por la Asamblea Legislativa en un momento coyuntural histórico en Costa Rica, cuando los medios de comunicación colectiva daban a conocer supuestos actos de corrupción de ex presidentes de la República, y altos directivos de instituciones públicas. La Ley General de Control Interno nace a la vida jurídica en el mismo periodo legislativo que la Ley contra la Corrupción y el Enriquecimiento llícito en la Función Pública, con ello el poder político aspiraba a cumplir con las demandas ciudadanas por una función púbica más ética, transparente y responsable. 
Como aspecto previo, se consultó al Área de Denuncias de la Contraloría General de la República, sobre la cantidad de denuncias en contra de funcionarios públicos por supuestas infracciones a la Ley General de Control Interno del año 2009 a la fecha. En Oficio DFOE-DI-470 del 27 de febrero 2014, se indica los datos de la tabla 3.

TABLA 3

\section{CANTIDAD DE DENUNCIAS RELACIONADAS CON LA LEY DE GENERAL DE CONTROL INTERNO}

\begin{tabular}{|c|c|}
\hline Año & Cantidad de casos \\
\hline 2009 & 36 \\
\hline 2010 & 44 \\
\hline 2011 & 9 \\
\hline 2012 & 19 \\
\hline 2013 & 19 \\
\hline 2014 & $1^{*}$ \\
\hline Total general & 128 \\
\hline
\end{tabular}

Fuente: Base de datos del Sistema de Denuncias (SIDE), Área de Denuncias e Investigaciones, Contraloría General de la República.

En la Tabla 1 que se comentó al inicio de este artículo, se denota cuando entramos en las normas específicas relativas a la Ley General de Control Interno, las denuncias bajan en una cantidad importante, pero en todo caso deben ser investigadas y canalizadas por el ente contralor.

El Artículo 1 de la LGCl inicia estableciendo los contenidos mínimos que deberá observar la CGR, así como los entes y sujetos fiscalizados en el mantenimiento, perfección y evaluación de los sistemas de control interno.

Para efectos de la eventuales responsabilidad, la LGCl en su Articulo 2, define al Jerarca como máxima autoridad, del órgano o entidad y al titular subordinado, como aquel colaborador responsable de un proceso con autoridad para ordenar y tomas decisiones.
En el capítulo segundo de la $\mathrm{LGCl}$, resulta de relevancia la definición del sistema de control interno. El Artículo 7 dispone que las entidades sujetas a esta ley deberán de contar con un sistema de control interno que resulte aplicable, sea congruente, y que establezcas las atribuciones y competencias de los colaboradores y autoridades.

Este artículo 7 es de suma importancia, ya que encontramos un "principio de legalidad en materia de control interno" (si se le puede llamar de este modo) el cual ordena que tiene que existir una definición legal, dentro de cada institución u organización donde la Ley General de Control Interno sea de aplicación, que establezca claramente los funcionarios, las funciones, las competencias o atribuciones dentro de la temática del Control Interno.

Frecuentemente se menciona en los medios de comunicación colectiva, que muchos casos por supuestos delitos contra la Hacienda Pública quedan en la impunidad, por cuanto no logra establecerse con claridad quien fue la persona concreta que lesionó al Erario Público. En razón de esto, el que las instituciones y organizaciones publicas logren consolidar sus sistemas de control interno contribuye a erradicar la impunidad y fortalecer la credibilidad y la democracia costarricense.

Por su parte, el Sistema de Control Interno se entenderá en el Articulo 8 de la LGCl como aquella serie de acciones tendientes a garantizar seguridad en la consecución de los siguientes objetivos: a) evitar el despilfarro de los fondos públicos, protegiendo y conservando los mismos, b) exigir confiabilidad y oportunidad de la información, c) garantizar la eficacia y la eficiencia de las operaciones y d) cumplir con el ordenamiento jurídico y técnico.

El Articulo 8 de la LGCl hay que complementarlo con el Artículo 8 de la LOGCR, el cual define lo que es Hacienda Publica. La Ley de Control 
Interno hace un llamado para que los funcionarios públicos tengan presente y la ciudadanía en términos generales, que los fondos públicos no son solamente "dinero efectivo" que puedan manejar las instituciones u organizaciones públicas; sino que es todo bien propiedad del Estado que sea objeto de una inadecuada administración, sea bajo una figura abusiva, o bien para lograr un aprovechamiento ilegítimo del mismo, o en otra tipología de casos cuando no se toman las acciones necesarias para la conservación de un bien público quedando el mismo sujeto a una pérdida o deterioro.

\section{DE LAS RESPONSABILIDADES FUNCIONALES EN LA LEY GENERAL DE CONTROL INTERNO}

Habiendo comentado conceptos generales pero importantes en las partes iniciales de la Ley General de Control Interno, corresponde entonces comentar las responsabilidades funcionares de la Ley 8292.

El Artículo 12 de la Ley general de control Interno se denomina "Deber del Jerarca y de los titulares subordinados en el sistema de control interno". Desde el título mismo del Articulo que comentaremos, claramente se enuncia como un deber del jerarca y del titular subordinado. La palabra "deber" en una acepción correcta es "obligación", no dejando espacio para interpretaciones o bien conductas discrecionales del funcionario o del jerarca.

El articulo 12 inciso a) indica: "Velar por el adecuado desarrollo de la actividad del ente o del órgano a su cargo". Como se indicara para el tema de la "responsabilidad en general", tanto el Jerarca como el Titular subordinado deben "velar" por la actividad del ente. Sí bien es cierto, existe la figura de la delegación de funciones, traemos a colación la máxima "(...) se delega la función, mas no la responsabilidad". Por tanto, el Jerarca y el Titular subordinado tienen el deber de velar por la gestión haya sido o no esta delegada.

El Artículo 12 inciso b) dice: "Tomar de inmediato las medidas correctivas, ante cualquier evidencia de desviaciones o irregularidades". Este es un aspecto medular. En muchas organizaciones públicas las decisiones tienen que adoptarse en sesiones de Junta Directiva, en razón de ello, y dependiendo del asunto a tratar, debe incluirse con la mayor celeridad posible en la sesión del órgano colegiado para que sea de conocimiento y pueda ser adoptado el acuerdo correspondiente. De igual forma, si la medida correctiva no es adoptada a tiempo, y se generara algún perjuicio al erario público, podría enfrentarse una causa penal por incumplimiento de deberes en la función pública, además de cualquier tipo de sanción que disponga la Ley General de Control Interno. De igual forma, el titular subordinado o el Jerarca que lleva el asunto para conocimiento la medida correctiva a sesión de Junta Directiva debe demostrar sea por vía escrita, o por correcto electrónico la gestión que ha llevado a cabo; esto para exonerarse de cualquier responsabilidad por el conocimiento a destiempo de la medida correctiva.

El Articulo 12 inciso c) dispone: "Analizar e implantar, de inmediato, las observaciones, recomendaciones y disposiciones formuladas por la auditoría interna, la Contraloría General de la República, la auditoría externa y las demás instituciones de control y fiscalización que correspondan". Resulta de igual aplicación para el caso anterior. Existen instituciones públicas donde la implementación de medidas está sujeta a conocimiento, autorización de varias dependencias administrativas. Al ser normas de acatamiento obligatorio, es importante demostrar que la institución ha tomado las actuaciones administrativas necesarias sea en la fase de análisis y de aplicación todo dentro de un tiempo prudencial y razonable. Por lo tanto, tendrá 
el Jerarca o bien el Titular subordinado que respaldar su actuación, indicando que ha procedido dentro del marco de su competencia a trasladar el asunto a la fase que corresponda según el organigrama institucional, sea esto por vía correo electrónico o bien por escrito.

El Articulo 12 incisos d) y e) respectivamente dicen: "d) Asegurarse de que los sistemas de control interno cumplan al menos con las características definidas en el artículo 7 de esta Ley."; "e) Presentar un informe de fin de gestión y realizar la entrega formal del ente o el órgano a su sucesor, de acuerdo con las directrices emitidas por la Contraloría General de la República y por los entes y órganos competentes de la administración activa". En el caso del inciso d), es importante que el Jerarca de la institución al igual que titular subordinado supervise que los sistemas de control interno están cumplimiento con las disposiciones contenidas en la LGCl. Igualmente deben respaldar sus gestiones administrativas para eventuales acciones de responsabilidad funcional. En el tema de los informes de final de gestión, los jerarcas y los titulares subordinados que tenga la obligación de rendir este informe que deben cumplir con él mismo, según el formato que dispone la Contraloría General de la República.

Como partes integrantes del Sistema de Control Interno, el Jerarca y el Titular subordinado deben de velar por los siguientes: a) Ambiente de Control, Articulo 13; b) Valoración del Riesgo, Articulo 14; c ) Actividades de Control, Artículo 15; y los Sistemas de información del Artículo 16.

En el seguimiento de las acciones del Sistema de Control Interno, es un deber del Jerarca y del Titular subordinado designar los responsables de la evaluación de la calidad del Sistema y asegurar que los hallazgos efectuados por la Auditoría Interna sean adoptados lo más pronto posible.
Por su parte, el Artículo 40 de la LGCl establece la responsabilidad subjetiva de los funcionarios de la auditoria interna, incluido el auditor y el subauditor, cuando infrinjan con dolo o culpa grave la normativa técnica aplicable o vulneren el régimen de prohibiciones contemplado en el Artículo 34 de la LGCl.

Las sanciones administrativas que estipula la LGCl se encuentran contenidas en el Artículo 41, las cuales son: a) amonestación escrita, b) Amonestación escrita comunicada al colegio profesional respectivo, cuando corresponda, c) Suspensión, sin goce de salario, de ocho a quince días hábiles. En el caso de dietas y estipendios de otro tipo, la suspensión se entenderá por número de sesiones y el funcionario no percibirá durante ese tiempo suma alguna por tales conceptos y d) Separación del cargo sin responsabilidad patronal.

Todas esas sanciones administrativas serán impuestas en fiel y estricto cumplimiento de las garantías del debido proceso constitucional establecido en el Artículo 39 de la Constitución Política. La jurisdicción disciplinaria será llevada por el órgano competente que ostente la potestad según la normativa interna de cada institución.

Para el caso de miembros de supremos poderes, ministros, alcaldes, regidores, diputados, Contralor y Subcontralor, Defensor y Defensor Adjunto, tendrá que comunicarse de la falta sea al Consejo de Gobierno, al Tribunal Supremo de Elecciones, Corte Suprema de Justicia o bien a la Asamblea Legislativa para que procedan según el derecho a imponer la sanción respectiva.

Finalmente, el Artículo 43 LGCl remite al Artículo 71 LOCGR para efectos de determinar la prescripción para imponer la sanción, norma que indica: a) En los casos en que el hecho irregular sea notorio, la responsabilidad prescribirá en cinco años, contados a partir del acaecimiento del hecho; b) En los casos en que el hecho 
irregular no sea notorio -entendido este como aquel hecho que requiere una indagación o un estudio de auditoría para informar de su posible irregularidad- la responsabilidad prescribirá en cinco años, contados a partir de la fecha en que el informe sobre la indagación o la auditoría respectiva se ponga en conocimiento del jerarca o el funcionario competente para dar inicio al procedimiento respectivo.

Agrega también que cuando el autor sea el jerarca, el plazo de prescripción correrá a partir de la fecha en que termine su relación de servicio con el ente, empresa u órgano respectivo.
Dispone también que se reputará como falta grave del funcionario competente para iniciar el procedimiento sancionatorio el no darle inicio a este oportunamente, o el dejar que la responsabilidad del infractor prescriba, sin causa justificada.

Según la materia objeto de conocimiento y denuncia ante la Contraloría General de la República, se brinda la información de la tabla 4.

Finalmente, el reporte de sanciones por recomendación de la Contraloría se observa en la tabla 5.

TABLA 4

\section{CANTIDAD DE PROCEDIMIENTOS ADMINISTRATIVOS EN CURSO}

\begin{tabular}{|c|c|c|c|c|c|c|c|}
\hline \multicolumn{8}{|c|}{ Materias } \\
\hline Año & $\begin{array}{l}\text { Procedimientos } \\
\text { Administrativos }\end{array}$ & $\begin{array}{l}\text { Contratación } \\
\text { Administrativa }\end{array}$ & $\begin{array}{l}\text { Informes } \\
\text { DFOE }\end{array}$ & Investigación DJ & Consultiva & Otros & Total \\
\hline 1990-2007 & 10 & 8 & 11 & & 1 & 3 & 33 \\
\hline 2008 & & 2 & 3 & 2 & & & 7 \\
\hline 2009 & 3 & 4 & 3 & & & & 10 \\
\hline 2010 & 12 & 5 & 14 & 1 & 1 & 2 & 35 \\
\hline 2011 & 15 & 4 & 2 & 2 & & & 23 \\
\hline 2012 & 13 & 9 & 4 & & 2 & & 28 \\
\hline Total & 53 & 32 & 37 & 5 & 4 & 5 & 136 \\
\hline
\end{tabular}


TABLA 5

\section{CANTIDAD DE SANCIONES POR RECOMENDADAS UNA VEZ FINALIZADOS LOS PROCESOS}

\begin{tabular}{|l|c|c|c|c|c|c|c|}
\hline \multicolumn{1}{|c|}{ Detalle } & $\mathbf{2 0 0 8}$ & $\mathbf{2 0 0 9}$ & $\mathbf{2 0 1 0}$ & $\mathbf{2 0 1 1}$ & $\mathbf{2 0 1 2}$ & $\mathbf{2 0 1 3}$ & Total \\
\hline $\begin{array}{l}\text { Amonestación escrita } \\
\text { publicada }\end{array}$ & 10 & 11 & 17 & 13 & 13 & & 64 \\
\hline $\begin{array}{l}\text { Amonestación escrita } \\
\text { no publicada }\end{array}$ & 11 & 14 & 15 & & 3 & & 43 \\
\hline $\begin{array}{l}\text { Suspensión } \\
\text { Despido }\end{array}$ & 27 & 18 & 21 & 9 & 6 & & 81 \\
\hline $\begin{array}{l}\text { Prohibición de ingreso } \\
\text { o reingreso }\end{array}$ & 15 & 20 & 22 & 8 & 6 & 2 & 73 \\
\hline $\begin{array}{l}\text { Sanción por } \\
\text { responsabilidad civil }\end{array}$ & 95 & 105 & 109 & 92 & 53 & 2 & 456 \\
\hline
\end{tabular}

Fuente: Bases de Datos, División Jurídica, Contraloría General de la República.

\section{CONCLUSIONES}

La sociedad costarricense demanda actualmente mayores y más efectivos controles en el manejo de la Hacienda Pública. Los componentes de dicha hacienda, son pagados con recursos de todos los habitantes de este país, y por lo tanto existe un deber ético en primera instancia del funcionario público en cuidar y proteger dichos bienes contra cualquier acción indebida, irregular, de despilfarro o gasto indebido.

El Artículo 11 de la Constitución Política de Costa Rica, que consagra el principio de legalidad, como un límite al ejercicio del poder y de las competencias administrativas de los funcionarios públicos, es una cimento importante para la construcción y interpretación del sistema de control interno.

La Contraloría General de la República por disposición de los Artículos 183 y 184 de la Constitución Política, es una institución independiente funcional y administrativamente para la defen- sa y salvaguarda de la Hacienda Pública. Por lo tanto la Contraloría ostenta una competencia exclusiva y prevalente para accionar, demandar y recomendar sanciones contra los funcionarios que hayan sido encontrados infractores por conductas contrarias a la Ley.

El Artículo 39 de la Constitución Política de Costa Rica, establece como un derecho fundamental "el debido proceso" para efecto de imponer sanciones administrativas. Por desarrollo amplio de la jurisprudencia vinculante de la Sala Cuarta Constitucional, se han construido una serie de principios que son de cumplimiento obligatorio para la Administración como un adecuado derecho de defensa a favor del funcionario objeto de investigación.

Los principios del proceso penal son de aplicación en el derecho administrativo sancionatorio, ya que dichos principios integran y contribuyen a un ejercicio adecuado y suficiente del derecho de la defensa y del debido proceso en sede administrativa. 
La Ley General de la Administración Pública contiene como norma rectora, el principio de responsabilidad subjetiva del funcionario público. En los artículos 211 al 213 de ese cuerpo normativo encontramos claras normas que hacen referencia al tipo de responsabilidad por la comisión de conductas dolosas o con culpa grave de los colaboradores públicos.

Los tipos de responsabilidad general que contiene La Ley General de la Administración Pública son de variada índole y no son excluyentes entre sí; entre ellas se encuentra la responsabilidad civil, penal, administrativa, disciplinaria, y por delegación. La imposición simultanea de estos tipos de responsabilidad frente a una misma conducta infractora es avalado por la Jurisprudencia de la Sala Cuarta Constitucional, de la Procuraduría y la Contraloría General de la República.

La Ley General de Control Interno instaura como principio rector en su ámbito de aplicación para la construcción del Sistema de Control la seguridad tanto en la información, en la implementación y en la evaluación de los sistemas de control.

La responsabilidad que establece claras causales de responsabilidad administrativa que se contemplan en los artículos del 39 al 41 en la Ley General de Control Interno. Se sancionan tanto las conductas activas como omisivas en la aplicación de normativa técnica, implementación de recomendaciones de la Auditoria Interna, violación a los impedimentos funcionales para los funcionarios de Auditoria Interna, Auditor y Subauditor. De igual forma se sanciona al Jerarca y al Titular Subordinado por no adoptar en tiempo medidas tendientes a la protección y salvaguarda del patrimonio público, así como no ejecutar las acciones necesarias para la implementación de un ambiente de control.

La Ley Orgánica de la Contraloría General en su Artículo 71 por remisión de la Ley General de Control Interno en su Artículo 43, establece los plazos de prescripción del ejercicio de la acción disciplinaria, estableciéndose como una pauta general los 5 años.

Una vez analizado todo el espectro de responsabilidad que contiene la Ley General de Control Interno, ésta llama a una reflexión importante a todos los funcionarios públicos sobre la importancia de propiciar un clima propicio para el ejercicio de una función pública más responsable. El funcionario Público es un mero detentador de una serie de competencias administrativas, y su labor es servir a todos los habitantes de este país. Igualmente, hay una labor muy importante que se hace desde la Contraloría General de la República como un garante imparcial de la probidad en la función pública.

Todos los funcionarios públicos son responsables ante la Ley por sus actuaciones dolosas o culposas o bien hasta omisivas en el resguardo y defensa de los bienes públicos, y en razón de ello debe promoverse por parte de las instituciones públicas mayores labores de capacitación y concientización sobre el alcance en materia de responsabilidad que les pueden afectar.

Dichas labores de fomentar una cultura preventiva y capacitación continua, así como el rol fundamental que ejercen las instituciones de fiscalización superior contribuirán a fomentar un ejercicio más consciente así como responsable en la función publica, y esto sin duda fortalecerá la democracia de Costa Rica para las presentes y futuras generaciones.

\section{REFERENCIAS}

Asamblea Legislativa de Costa Rica (1949). Constitución Política de Costa Rica. Recuperado de http://www.mtss. go.cr/legislacion-laboral/constitucion-politica-decosta-rica.html

Asamblea Legislativa de Costa Rica. (2004). Ley Contra la Corrupción y el Enriquecimiento Ilícito en la Función Publica. Recuperado de http://www.pgrweb.go.cr/scij/ Busqueda/Normativa/Normas/nrm_texto_completo. 
aspx?param $1=$ NRTC $\&$ nValor $1=1 \&$ nValor $2=53738 \& n V a$ lor3 $=90841 \&$ strTipM $=$ TC

Asamblea Legislativa de Costa Rica. (1978). Ley General de la Administración Pública. Recuperado de http://www.ocu.ucr.ac.cr/Leyes/Ley_Administracion_Publica.pdf

Asamblea Legislativa de Costa Rica. (2002). Ley General de Control Interno. Recuperado de http:// www.ocu.ucr.ac.cr/Leyes/Ley_8292_Control_Interno.pdf

Asamblea Legislativa de Costa Rica. (1994). Ley Orgánica de la Contraloría General de la República. Recuperado de http://cgrw01.cgr.go.cr/portal/page?_pageid $=434,1810503 \&$ dad $=$ portal\&_schema=PORTAL

Brewer Carias, A. (2003). Principios del Procedimiento Administrativo. Colombia: Editorial Legis

Escola, H. (1981). Tratado General de Procedimiento Administrativo. Argentina: Editorial Depalma.

García de Enterría, E.(2000). Curso de Derecho Administrativo, tomo II. España: Editorial Civitas.

Nieto, A. (2002). Derecho Administrativo Sancionador. España: Editorial Tecnos (grupo Anaya S.A.).

Contraloría General de la República (2014). Resolución DFEO-DI-470-2014. Recuperada de www.cgr.go.cr

Contraloría General de la Republica (2006). Resolución DAGJ-0631-2006. Recuperada de www.cgr.go.cr

Contraloría General de la Republica (2005). Resolución FOEEC-414. Recuperada de www.cgr.go.cr

Contraloría General de la Republica (2005). Resolución D/CR-421. Recuperada de www.cgr.go.cr

Contraloría General de la Republica (2005). Resolución D/CR-325. Recuperado de www.cgr.go.cr

Contraloría General de la Republica (2005). Resolución DAGJ-0961-2005. Recuperado de www.cgr.go.cr

Contraloría General de la Republica (2004). Resolución DICR-565. Recuperado de www.cgr.go.cr

Contraloría General de la Replica (2004). Resolución D/CR-230. Recuperado de www.cgr.go.cr

Procuraduría General de la Republica (2005). Resolución C-128-2005. Recuperado de www.pgr.go.cr
Procuraduría General de la Republica (2005). Resolución C-123-2005. Recuperado de www.pgr.go.cr

Procuraduría General de la Republica (2004). Resolución C-374-2004 Recuperado de www.pgr.go.cr

Procuraduría General de la Republica (2004). Resolución C-342-2004. Recuperado de www.pgr.go.cr

Procuraduría General de la Republica (2000). Resolución C-112-2000. Recuperado de www.pgr.go.cr

Procuraduría General de la Republica (2000). Resolución C-062-2000. Recuperado de www.pgr.go.cr

Procuraduría General de la Republica (1999). Resolución C-034-1999. Recuperado de www.pgr.go.cr

Sala Constitucional, Corte Suprema de Justicia (2004). Resolución Voto 2004-0567. Recuperado de www.poderjudicial.go.cr

Sala Constitucional, Corte Suprema de Justicia (2004). Resolución 2003-13140. Recuperada de www.poderjudcial.go.cr

Sala Cuarta Constitucional, Corte Suprema de Justicia (2000). Resolución Voto 2000-07203. Recuperado www. poder-judicial.go.cr

Sala Constitucional, Corte Suprema de Justicia (1994). Resolución 2945-94. Recuperado de www.poder-judicial. go.cr

Sala Constitucional, Corte Suprema de Justicia (1999). Resolución 632-1999. Recuperado de www.poder-judicial. go.cr

Sala Constitucional, Corte Suprema de Justicia (1998). Resolución 2376-1998. Recuperado de www.poderjudicial.go.cr
Recibido: 10 de enero de 2014 Aceptado: 23 de febrero de 2014 